\title{
Predictive Role of Boredom Proneness and Self-Efficacy on Perceived Stress among Civil Servants Working from Home during COVID-19 Lockdown
}

\author{
Taofeeq A. Olaigbe ${ }^{1 *}$, Dare A. Fagbenro ${ }^{2}$, Kolawole S. Adebisi ${ }^{3}$
}

\section{ABSTRACT}

The study investigates the predictive role of boredom proneness and self-efficacy on perceived stress among civil servants working from home during COVID-19 lockdown in Ibadan metropolis. The study adopted a cross-sectional survey using an anonymous online questionnaire to collect data from respondents. A snowball sampling technique was employed to recruit 206 participants (136 males and 70 females) with a mean age of 42.11 (SD of 4.12) recruited from Ibadan metropolis. Data were analyzed using hierarchical multiple regression analysis and t-test for independent sample. Result showed that boredom proneness and selfefficacy jointly predicted perceived stress $\left(\mathrm{R}^{2}=0.21, F(2,203)=30.54, p<.01\right)$. Finally, there was no gender difference in perceived stress among civil servants [ $\mathrm{t}(204)=-1.37, \mathrm{p}>.05]$. Based on these findings, the study concluded that boredom proneness and self-efficacy are determinants of perceived stress among civil servants during COVID-19 lockdown. We therefore recommended that behavioural scientists should design intervention programme tailored toward reducing boredom proneness and boosting self-efficacy of all civil servants such that it will help reduce stress during and after COVID-19 lockdown.

Keywords: Perceived stress, boredom proneness, self-efficacy, COVID-19

$\mathrm{T}$

The rampaging COVID-19 pandemic affected all spheres of life including workplace activities globally and in Nigeria. In a bid to curtail the spread of the virus, precautionary measures such as lockdown of public places were ordered by government at all levels. This means that civil servants especially the lower cadre were directed to work from home. The change in work environment predisposes many staff to perceived stress. Stress is the reaction of a person to events, and depending on how the individual reacts, it may be positive or negative. Stress also indicates the general wear and tear of body machinery, either physically or psychologically, as a result of the additional demands placed on it. A minimal level of stress is required for human being but when it is much it tends to affect individual overall functioning and wellness. Essentially, Willemen,

${ }^{1}$ Department of General Studies, The Polytechnic, Ibadan, Nigeria

${ }^{2}$ Department of Psychology, Obafemi Awolowo University, Osun State, Nigeria

${ }^{3}$ Department of General Studies, The Polytechnic, Ibadan, Nigeria

*Responding Author

Received: December 28, 2020; Revision Received: February 18, 2021; Accepted: March 03, 2021

(C) 2021, Olaigbe T.A., Fagbenro D.A. \& Adebisi K.S.; licensee IJIP. This is an Open Access Research distributed under the terms of the Creative Commons Attribution License (www.creativecommons.org/licenses/by/2.0), which permits unrestricted use, distribution, and reproduction in any Medium, provided the original work is properly cited. 


\section{Predictive role of boredom proneness and self efficacy on perceived stress among civil servants working from home during covid-19 lockdown}

Koot, Ferdinand and Goossens (2008) define perceived stress as an individual expression of difficulty in meeting demands within important life domains. During the COVID-19 lockdown many of the workers were faced with different form of stressor as a result of working from home. These stressors include but not limited to pressure meeting up work deadlines, communication gap, poor internet network, anxiety regarding COVID-19 new update as well as family responsibilities etc. Cursory observation showed that these challenges contributed negatively to work commitment and job performance of civil servants during the pandemic. Studies such as (Colligan \& Higgins 2005; Anderson \& Puluch, 2001; Gosselin, Bourgault, \& Lavoie 2016; Wang et al., 2015; Ashton, 2017) reported that work related stress have negative consequences in civil servants population, which includes lower productivity, increase absenteeism, poor employee wellbeing and cardiovascular disorders. Studies on perceived stress and its associated factors in developed world and in Nigeria have being documented in the literature (Nwimo \& Onwunaka, 2015; Mansour \& Mohanna, 2017; Jamal, Zahra, Yaseen, \& Nasreen 2017; Bawo et.al 2017; Akinsulore, et.al 2020). However, this study is the first according to the researchers' knowledge to investigate the predictive role of boredom proneness and self-efficacy on perceived stress among civil servants working from home during COVID-19 lockdown.

Boredom proneness refer to unpleasant affective state in which individual feels a pervasive lack of interest in and difficulty concentrating on the current activity. The loss of interest and difficulty concentrating on work role at home could have predisposes many civil servants to have experience negative behaviour such as stress. Research has demonstrated that boredom relates to a variety of negative outcomes such as low effort and performance, job dissatisfaction, absenteeism, turnover intentions, counterproductive work behaviour, stress and work injuries (Frone, 1998; Kass, Vodanovich, Stanny, \& Taylor, 2001; Bruursema, Kessler, \& Spector, 2011; Reijseger et al., 2013). Adeyemo and Agokei (2010) described self-efficacy as the belief in one's ability to perform successfully. Fakeye (2010) also sees self-efficacy as the assumptions of individual in their own ability to perform a task. Selfefficacy can be classified as either high or low, according to Bandura (1997). Individual with high self-efficacy have the tendency to meets up challenges in life while low self-efficiency are individual who are unable to cope with the life challenges. They give up quickly in the face of difficulties as well as fall easily to stress and depression (Bandura, 2000). It is therefore can be said that when civil servants have high self-efficacy it could help reduce the experience of stress. Also, existing studies also indicate that self-efficacy have influence on work related stress (Vaezi, \& Fallah 2011; Gladys 2012). Also, understanding gender difference in perceived stress of civil servants may offer gender-based recommendations. To support this preposition, Nwimo, and Onwunaka (2015), Philips, Sen and McNamee (2007), Hanif, Tariq and Nadeem (2011) and Aderibigbe, Mjoli and Adebisi (2018) all found in their study significant gender differences in the level of perceived stress. Thus, we aim to fill some gaps identified in the literature by examining the role of boredom proneness and selfefficacy on perceived stress among civil servants in Ibadan, Nigeria. Also, the study sets to test the difference in perceived stress of male and female civil servants.

\section{Hypotheses}

- There will be significant joint and independent prediction of boredom proneness and self-efficacy on perceived stress among civil servants

- There will be significant gender difference on perceived stress among civil servants 


\section{Predictive role of boredom proneness and self efficacy on perceived stress among civil servants working from home during covid-19 lockdown}

\section{MATERIALS AND METHODS}

\section{Research design, setting and participants}

The study adopted a cross-sectional survey using an anonymous online questionnaire to collect data from respondents. Prospective respondents were purposively sent the link via Social media (WhatsApp and Facebook posts) and asked to participate in an online survey. Socio-demographic characteristics of the participants revealed that 206 participants (136 males and 70 females) with a mean age of 42.11 (SD of 4.12). In terms of religion affiliation, $75 \%$ of the respondents claimed to be Christian, 22\% were Muslim and the remaining 3\% claimed other religion. In terms of ethnicity, $66 \%$ were Yoruba, $14 \%$ were Igbo $8 \%$ were Hausas and $12 \%$ belong to other ethnic groups. In terms of marital status majority $66 \%$ of the participants were married, $33 \%$ were never married while only $1 \%$ was divorced as at the time of the study. Lastly, in term of civil servant type, majority $67 \%$ claimed they work for federal government of Nigeria while 23 claimed they work for state government.

\section{Measures}

A structured questionnaire was used to collect data which consist of demographic characteristics of the respondents and reliable scales for measuring variables of interest in the study.

Boredom Proneness was measured using the 8 item Boredom Proneness Scale (BPS) developed by Struk, Jonathan, Carriere, Cheyne and Danckert (2015). Sample on the scale reads" In most situations, it is hard for me to find something to do or see to keep me interested'. The scale was scored on 7-point Likert-type ranging from strongly disagree to strongly agree. The author reports a reliability of 0.85 . In this study a Cronbach alpha of 0.79 was reported.

Perceived stress was measured using the 14 item Perceived Stress Scale (PSS) developed by Cohen, Kamarck and Mermelstein (1983) The scoring is done on a 5-point scale ranging from $0=$ never, to $4=$ very often). Sample of the item on the scale reads "In the last month, how often have you been upset because of something that happened unexpected". High scores describe higher levels of perceived stress while low score indicates low perceived stress. The author reports a reliability of 0.82 . The scale yielded a Cronbach alpha of 0.87 in the study.

Self-efficacy was also assessed using the 10 item self-efficacy scale developed by Schwarzer and Jerusalem (1995). The item sample reads " I am confident that I can deal with unexpected events effectively." The answer format varies from $1=$ not true at all to $4=$ true precisely. A higher score indicates higher self-efficacy while a lower score shows low selfefficacy. The authors reported a reliability coefficient of 0.82 . The scale yielded a Cronbach alpha of 0.75 in the study.

\section{Procedure}

Due to the curfew imposed by the Oyo state government as well as ability to maintain the precautionary measures of physical/social distance of COVID-19, physical distribution of questionnaires was not possible, hence the study used the online survey in which link to the survey questions on Google form was sent to all consenting participants. A detailed informed consent form was attached at the beginning of the online questionnaire and consent was a prerequisite to continue in the survey. The data collection was initiated on May 5,

(c) The International Journal of Indian Psychology, ISSN 2348-5396 (e)| ISSN: 2349-3429 (p) | 323 


\section{Predictive role of boredom proneness and self efficacy on perceived stress among civil servants}

working from home during covid-19 lockdown

2020 and closed on June 3, 2020. A snowball sampling technique was employed in which Two hundred and six (206) were recovered through Google form which was processed for statistical analysis.

\section{Data analysis}

Descriptive analysis was used to analyse socio demographic factors of the respondents while inferential statistic (hierarchical multiple regression and t-test for independent measure) was used to test the hypotheses all through the IBM SPSS version 24.

\section{RESULTS}

\section{Test of Relationships among the Study Variables}

The correlation coefficients between the investigated variables are presented in Table 1.

Table 1. Zero order Correlation, mean, and standard deviations of all variables

\begin{tabular}{llllllll}
\hline & Variables & Mean & SD & N & 1 & $\mathbf{2}$ & $\mathbf{3}$ \\
\hline 1 & Boredom Proneness & 46.75 & 14.97 & 206 & - & & \\
2 & Self-efficacy & 19.04 & 3.58 & 206 & $.29^{* *}$ & - \\
3 & Perceived stress & 17.50 & 5.55 & 206 & $.26^{* *}$ &.$-35^{* *}$ & \\
$* * * p<.05$ & & & & &
\end{tabular}

The result above shows that there was significant positive relationship between boredom proneness and perceived stress $[\mathrm{r}(204)=.29, \mathrm{p}=.05]$. This finding implies that increase in boredom proneness tends to increase in perceived stress. Also, there was significant positive relationship between self-efficacy and perceived stress [ $\mathrm{r}(204)=.-35 \mathrm{p}<.05]$. The finding also implies that increase in self-efficacy tends to increase in perceived stress.

\section{Hypotheses 1}

There will be significant joint and independent prediction of boredom proneness and selfefficacy on perceived stress among civil servants

Table 2: Hierarchical multiple regression analysis showing the joint and independent predictive role of boredom proneness and self-efficacy on perceived stress

\begin{tabular}{lcccc}
\hline & \multicolumn{3}{c}{ Model I } & Model II \\
\hline Predictors & $\boldsymbol{\beta}$ & $\mathrm{t}$ & $\boldsymbol{\beta}$ & $\mathrm{t}$ \\
\hline Boredom proneness & .38 & $7.82^{* *}$ & .38 & $7.79^{* *}$ \\
Self-efficacy & & & .45 & $12.20^{* *}$ \\
\hline $\mathbf{R}$ & 0.38 & & 0.47 & \\
$\mathbf{R}^{2}$ & 0.15 & & 0.21 & \\
Adj $\mathbf{R}^{\mathbf{2}}$ & 0.15 & 0.21 & \\
$\mathbf{R 2}$ change (\%) & 0.15 & 0.23 & \\
$\boldsymbol{D} \boldsymbol{F}$ & 1,204 & & 2,203 & \\
$\boldsymbol{F}$ & $61.21^{* *}$ & & $30.54^{* *}$ & \\
$\boldsymbol{F}$ change & $61.21^{* *}$ & & $14.04^{* *}$ & \\
\hline
\end{tabular}

$* * p<.01$

Results of a two-model hierarchical multiple regression in Table 1 showed that at first model, boredom proneness significantly predicted perceived stress $\left(\mathrm{R}^{2}=0.15, \mathrm{~F}(1,204)=\right.$ $61.21, p<.01)$ and accounted for $15 \%$ of the variation in perceived stress. Addition of self- 


\section{Predictive role of boredom proneness and self efficacy on perceived stress among civil servants working from home during covid-19 lockdown}

efficacy in second model led to a significant increase to $21 \%$ of variation in perceived stress with joint contribution to the regression model $\left(\mathrm{R}^{2}=0.21, F(2,203)=30.54, p<.01\right)$. Similarly, at the second model, boredom proneness $(\beta=.38, \mathrm{p}<.01)$ and self-efficacy $(\beta=$ $.45, \mathrm{p}<.01)$ independently predicted perceived stress among civil servants.

\section{Hypothesis 2}

Table 3: Summary of Independent Sample t-test of male and female on perceived stress

\begin{tabular}{llllllll} 
Variables & Gender & N & Mean & Std & df & $\boldsymbol{t}$ & $\boldsymbol{p}$ \\
\hline Perceived stress & Male & 136 & 12.72 & 2.46 & 204 & -1.37 & $>.05$ \\
& Female & 70 & 8.40 & 1.50 & & & \\
\hline
\end{tabular}

The Table above revealed that there no difference in the likeness between male and female civil servants on perceived stress $[\mathrm{t}(204)=-1.37, \mathrm{p}>.05]$.

\section{DISCUSSION}

This study examined the predictive role of boredom proneness and self-efficacy on perceived stress among civil servants. Based on the hypotheses postulated, the study found that there was joint and independent prediction of boredom proneness and self-efficacy on perceived stress among civil servants. This finding was supported by (Stanny, \& Taylor, 2001; Bruursema, Kessler, \& Spector, 2011; Reijseger et al., 2013) where they all found that boredom proneness predictive negative behaviours including stress. The study finding was also in accordance with Vaezi, and Fallah (2011) as well as Gladys (2012) where they all found that self-efficacy have influence on work related stress. The justification why this finding was so is because the anxiety during the COVID-19 Pandemic and lockdown caused many workers working from home to loss interest in many thing including work roles which predisposes them to stress. Therefore, the way workers were able to handle work roles at home may explain why some workers perceive low or high stress during that time. The study also found that there was no gender difference in perceived stress. The finding was not in line with studies (Nwimo, \& Onwunaka 2015; Philips, Sen \&McNamee 2007; Hanif, Tariq \& Nadeem 2011; Aderibigbe, Mjoli \& Adebisi 2018) who all found in their study significant gender differences in the level of perceived stress. The rationale for this finding was because both gender while working at home have no partner or colleagues to call for assistance, hence the level of stress was the same for the gender. Also, the negative impact of the COVID-19 pandemic could have equally trigger a lot of stress among both gender.

\section{CONCLUSION AND STUDY IMPLICATIONS}

In view of our findings in this study, we concluded that boredom proneness and self-efficacy predicted perceived stress of civil servants working from home during COVID-19 pandemic. Finally, the study also concluded that there is no gender difference in perceived stress among civil servants working from home during COVID-19 pandemic. The study therefore implies that in order to address the problem of stress of civil servants working from home, there should be an interventional programmes targeted toward reducing boredom proneness as a risk factor and boasting self-efficacy as a protective factor among this set of important workers especially as experts predict another second wave of the COVID-19 pandemic which could lead to another lockdown thereby making civil servants to work from home. We therefore recommended that behavioural scientists should design intervention programme tailored toward reducing boredom proneness and boosting self-efficacy of all civil servants such that it will help reduce perceived stress during and after the COVID-19 


\section{Predictive role of boredom proneness and self efficacy on perceived stress among civil servants working from home during covid-19 lockdown}

lockdown. Finally, government at all levels should also provide adequate support for male and female civil servants while they are working from home. This could also make them perceive stress at a minimal level.

\section{Limitation and suggestion for further studies}

The study has contributed immensely to the stress literature; despite that there are some limitations. Firstly, the sample size is relatively small hence generalising the result to other civil servants in Nigeria and in the world could be challenging. Secondly, the method of data collection involves only online survey which could have tends some form of bias as well as restrict responses of respondents in the study. The study therefore suggests that sample size should be improved upon by future researchers. Also method of data collection can be improved upon by future study by including qualitative data i.e interview and FGD in order to have a robust result finding.

\section{REFERENCES}

Aderibigbe, K., Mjoli, Q., \& Adebisi, S. (2018). Role of Psychological Capital in Effective Management of Work-stress among Tertiary Institutions' Staff in Nigeria. Journal of Economics and Behavioral Studies, 10(2), 6-13

Adeyemo, D.A., \& Agokei, R.C (2010). The moderating effect of mindfulness on the link between counseling self-efficacy and counseling effectiveness among pre-practical trainee in some Nigerian Universities. Journal of Applied Psychology, 12(1), 1-18.

Akinsulore, A., Adegbenro, C., Balogun, Y., Elekwachi, G., Babalola, O., \& Akinlua, F. (2020).Perceived Stress and its Relationship with Coping Strategies among Doctors at a Tertiary Hospital in Ile-Ife, Nigeria. West African Journal of Medicine, 37(2), 146-151

Anderson, P. \& Pulich, M. (2001). Managing workplace stress in dynamic environment. Health Care Manager, 19, 1-10

Ashton, A. S. (2017). How human resources management best practice influence employee satisfaction and job retention in the Thai hotel industry. Journal of Human Resources in Hospitality \& Tourism, 14, 1-25

Bandura, A. (2000). Cultivate self-efficacy for personal and organizational effectiveness. Retrieved from http://www.pv-psg.org/file/R-9pdf. 21stAugust 2010

Bandura, A. (1997). Self-efficacy: The exercise of control. New York: Freeman

Bawo J., Ibironke F., Joyce O., Esther O., Kingsley M., Abdu W., Auwal S., Yewande O., Andrew. O., Paul C., George O., Godwin C., \& Benjamin E. (2020). Psychosocial correlates of perceived stress among undergraduate medical students in Nigeria. International Journal of Medical Education, 8, 382-388

Bruursema, K., Kessler, S. R., \& Spector, P. E. (2011). Bored employees misbehaving: The relationship between boredom and counterproductive work behavior. Work \& Stress, 25, 93-107. doi:10.1080/02678373.2011 .596670

Cohen, S., Kamarck, T., \& Mermelstein, R. (1983) A global measure of perceived stress. Journal of Health \& Social Behaviour, 24, 385-396

Colligan, T.W \& Higgins, E.M. (2005). Workplace Stress: Etiology and Consequences. Journal of workplace Behavioural Health, 21(2), 89- 97

Frone, M. R. (1998). Predictors of work injuries among employed adolescents. Journal of Applied Psychology, 83, 565-576. doi:10.1037/0021-9010.83.4.565

Gladys, P (2012). Emotional intelligence and self-efficacy as predictors of occupational stress among the senior secondary school teachers in Nigeria. Knowledge Review, 26(2), 139-145

(c) The International Journal of Indian Psychology, ISSN 2348-5396 (e)| ISSN: 2349-3429 (p) | 326 


\section{Predictive role of boredom proneness and self efficacy on perceived stress among civil servants working from home during covid-19 lockdown}

Gosselin, E., Bourgault, P., \& Lavoie, S. (2016). Association between job strain, mental health and empathy among intensive care nurses. Nursing in Critical Care, 21(3), 137-145. https://doi.org/10.1111/nicc.1206

Hanizah, M.Y. (2003). The effect of information technology usage on the prevalence of stress among school teachers in Selangor and factors affecting the stress. Unpublished Master's Thesis, Universiti Kebangsaan, Malaysia..

Jamal, Y., Zahra, Yaseen, T., \& Nasreen, N. (2017). Coping Strategies and Hardiness as Predictors of Stress among Rescue Workers. Pakistan Journal of Psychological Research, 32,(1), 141-154

Kass, S. J., Vodanovich, S. J., \& Callender, A. (2001). State-trait boredom: Relationship to absenteeism, tenure, and job satisfaction. Journal of Business and Psychology, 16, 317-327. doi:10.1023/A:1011121503118

Mansour, S., \& Mohanna, D. (2017). Mediating role of job stress between work-family conflict, work-leisure conflict, and employees' perception of service quality in the hotel industry in France. Journal of Human Resources in Hospitality \& Tourism, 14, $1-21$

Nwimo, O., \& Onwunaka, C. (2015). Stress among Secondary School Teachers in Ebonyi State, Nigeria: Suggested Interventions in the Worksite Milieu. Journal of Education and Practice, 26(6), 93-100

Philips, S., Sen, D., \& McNamee, R. (2007). Prevalence and causes of self-reported workrelated stress in head teachers. Occupational Medicine, 57, 367-376.

Reijseger, G., Schaufeli, W. B., Peeters, M. C. W., Taris, T. W., Van Beek, I., \& Ouweneel, E. (2013). Watching the paint dry at work: Psychometric examination of the Dutch Boredom Scale. Anxiety, Stress, \& Coping, 26, 508-525. doi:10.1080/10615806.2012.720676

Schwarzer, R., \& Jerusalem, M. (1995). Generalized self-efficacy scale. In J. Weinman, S. Wright, \& M. Johnston (Eds.), Measures in health psychology: A user's portfolio. Causal and control beliefs (pp. 35-37). Windsor, UK: NFER-Nelson

Struk, A., Jonathan, S., Carriere, J., Cheyne, A., \& Danckert, J. (2015). A Short Boredom Proneness Scale: Development and Psychometric Properties. Assessment, 1-14

Vaezi S, \& Fallah N. (2011). The Relationship between Self-efficacy and Stress among Iranian EFL Teachers. Journal of Language Teaching and Research, 2(5), 11681174. Available from: ojs.academypublisher.com/index.php/jltr/article/download/

Wang, Y., Ramos, A., Wu, H., Liu, L., Yang, X., Wang, J., \& Wang, L. (2015). Relationship between occupational stress and burnout among Chinese teachers: A cross-sectional survey in Liaoning, China. International Archives of Occupational and Environmental Health, 88(5), 589-597. https://doi.org/10.1007/s00420-014-0987-9

Willemen, A., Koot, H., Ferdinand, R., Goossens, F., \& Schuengel, C.(2008). Change in psychopathology in referred children: The role of life events and perceived stress. Journal of Child Psychology and Psychiatry, 49(11), 12-23

\section{Acknowledgement}

The author appreciates all those who participated in the study and helped to facilitate the research process.

\section{Conflict of Interest}

The author declared no conflict of interest. 
Predictive role of boredom proneness and self efficacy on perceived stress among civil servants working from home during covid-19 lockdown

How to cite this article: Olaigbe T.A., Fagbenro D.A. \& Adebisi K.S. (2021). Predictive role of boredom proneness and self-efficacy on perceived stress among civil servants working from home during covid-19 lockdown. International Journal of Indian Psychology, 9(1), 321-328. DIP:18.01.036/20210901, DOI:10.25215/0901.036 